\title{
$\underline{\text { Research as the Researcher's Story }}$
}

By: W. Richard Cowling, RN; PhD and Mona M. Shattell, RN; PhD

Cowling, W.R., \& Shattell, M. (2007). Research as the researcher's story. Nursing Science Quarterly, 20(4), 315-318.

Made available courtesy of SAGE Publications: http://nsq.sagepub.com/

***Note: Figures may be missing from this format of the document

When we were given the challenge of expressing our views of research as the researcher's story, we intended to talk primarily about the ways in which our personal lives mediated our research work. While this remains one of the aspects of what we want to share, in our negotiations and conversations about writing this column we became aware of what brought us together to write a common article on this topic. We both share a commitment to research that is grounded in the ideals associated with participatory inquiry or what has been described as the participatory worldview (Reason \& Bradbury, 2001). This worldview has five defining features.

1. We live in a participatory world in which the reality we experience is a co-creative process with the universe. Heron (1996) described participation as fundamental to the nature of our being, an ontological given being subjective-objective. Reality is known through the form given it by the mind and simultaneously "the mind interpenetrates the given cosmos which it shapes" (p. 11).

2. According to a participatory worldview, human beings are inherently engaged and are acting and therefore "human inquiry is necessarily practical and a participatory form of inquiry is an action science" (Reason \& Bradbury, 2001, p. 8). In describing the implications of this perspective, Reason and Bradbury referred to the Scottish philosopher Macmurray's (1957) description of the self as agent. The participatory worldview embraces an epistemology in which knowledge primarily arises out of our activities having practical rather than theoretical objectives. The knowledge generated involves reflective theorizing. "The concept of 'action' includes the development of theory which may illuminate our action, guide it, and provide it with meaning" (Reason \& Bradbury, 2001, p. 8). In addition, human inquiry encourages us to explore relationships with others and provokes "questions of what is worthwhile, what values and purpose are worthy of pursuit" (Reason \& Bradbury, 2001, p. $8)$.

3. A participatory worldview asserts that there is a multiplicity of ways of knowing that originate from the relationships between us and others. Participation and intuition are essential aspects of these ways of knowing. According to Reason and Bradbury (2001), knowing the world requires extended epistemologies going beyond empirical and rational views of knowing. It is important that the researcher

develop "sensitivity and attunement in the moment of relationship" (p. 9). More than an academic enterprise, knowing through sensitivity and attunement is important in everyday relational practices and in creating meaning in our lives.

4. A participatory worldview is also a political statement that addresses the consequences of research and methods. It implies democratic, peer relationships among everyone involved in 
research. It transcends previous notions of research on or about people, and advocates for research with people as the primary mode of operation (Heron, 1996). "The political dimension of participation affirms that people's right and ability to have a say in decisions which affect them and which claim to generate knowledge about them" (Reason \& Bradbury, 2001, p. 9). The participatory worldview emphasizes the liberation of muted voices through the research process.

5. Researchers grounding their work in the participatory world- view generally agree "that the purpose of human inquiry is the flourishing of life, the life of human persons, of human communities, and increasingly of the more-than-human world of which we are a part"

(Reason \& Bradbury, 2001, p. 10). A participatory worldview suggests that we inquire into the meaning and purpose of our endeavors as researchers. The primary purpose of inquiry is more than a search for truth. It is a quest for healing, primarily to heal the alienation and fragmentation that characterizes modern experience. Thus, "a participatory worldview locates the practical response to human problems in its necessary wider, spiritual context" (Reason \& Bradbury, 2001, p. 11).

\section{The Participatory Worldview and the Story}

The five dimensions of a participatory worldview guide our research endeavors and inform our conceptualization of research as the researcher's story. Our intentional embrace of these perspectives requires that we reject the notion of research being the researcher's story alone. Rather we build a case that the inquiry strategies that we employ, consistent with our human and professional values, suggest that, research is my story and their (participants') story woven into our story; that is, the researchers and the participants' stories meet in conversation to create a greater story. This greater story gives rise to new knowledge that transcends individual stories. Given our fundamental participation in the whole that is the universe, we are engaged in story in the process of research. The story emerges from the interweaving of the five dimensions of the participatory worldview.

\section{A Participatory World}

The co-creative process of a participatory universe shapes the story of research. The story that is research in this universe is an evolutionary, emergent, and reflexive one in which there is a continual unfolding, patterning, and shaping of a story focused on a shared concern. The story originates from within each person as both "independent and linked in a generative web of communion" (Reason \& Bradbury, 2001, p. 8). The story contains and is known through its constructs and sensitivities. Constructs take the form of concepts, theories, and statements that are descriptive and explanatory generating a plot. Sensitivities are formed through the development of ourselves, researcher-participants, as instruments of inquiry and through shaping the methods that we use to develop the story plot and to interpret and share it. Constructs and sensitivities interact to shape the story that responds to the issues and concerns of researcherparticipants.

\section{Practical Being and Acting}

The story is necessarily a practical one that emerges from acting, the action of living and engagement with others. The story strives to uncover the multiple ways of knowing that support our skillful existence and being in the world. The story does not stand outside the experience of being and acting but rather is the research as cycles of actions and reflections occurring as the 
essence of the research story unfolding. The story's purposes relate to worthwhile living in a practical being and acting sense. All of our capacities as researcher- participants are employed in the creation of the story that is inquiry. As the story is being told all the authors (researcherparticipants) involved use their capacities, employing them to "articulate further the nature of knowing" (Reason \& Bradbury, 2001, p. 8). Likewise, the authors of the research (researcher and participants) are invited to consider their relationship with others, directing their "attention to what is worthwhile, what values and purpose are worthy of pursuit" (Reason \& Bradbury, 2001, p. 8). Thus, the story is authored mutually addressing and attending to the nature of knowing, relationships, values, and purpose.

\section{The Nature of Knowing}

As noted previously, diverse forms of knowing are drawn upon to compose the story as we engage with and act in participatory inquiry. The story embodies the lives of the researcherparticipants being the foundation for action within the story. The story is a subjective-objective story extending beyond traditional approaches to creating and writing the story. Facts and values of the researcher-participants are joined in the authoring of the story arising from a participatory mode of creation. The knowing of the storyline is a knowing that comes from within the inquiry enterprise that "arises in the process of living, in the voices of ordinary people in conversation" (Reason \& Bradbury, 2001, p. 9). The generation of the knowledge of the story is reflective and serves to represent itself in many ways, not just to tell the story, but to have the story change people's lives through the process of raising awareness or consciousness. Thus, the story of participatory inquiry has a strong emancipatory quality in its telling.

\section{The Political Dimension}

The participatory research story is one that requires democratic, peer relationships in the authoring of the story. The story that the research is generated from and "affirms peoples' right and ability to have a say in decisions which affect them" (Reason \& Bradbury, 2001, p. 9). The goal of the participatory inquiry story is to create shifts in power in favor of those who are most vulnerable and who have the least political power. Thus the story is a way to illuminate muted voices and encourage democratic social change. A participatory story is legitimized to the extent that it is constructed by and uses knowledge from the people whose lives it is intended to benefit. The story of participatory research is one of educating and developing capacities to improve life for the authors as well as the readers individually and collectively.

\section{Purpose and Meaning}

The story of participatory inquiry is a story of purpose and meaning extending beyond the practical, beyond social justice, beyond the quality of knowledge, encompassing all of these and reaching for the sacred (Reason \& Bradbury, 2001). "Sacred experience is based in reverence, in awe and love for creation, valuing it for its own right as a living presence" (Reason \& Bradbury, 2001, p. 10). Thus, the story is infused with purpose and meaning as conceptualized and articulated in participation by everyone engaged in the inquiry. The ideal participatory research story is one that provides a context for healing, a participatory healing within, through, and from the inquiry endeavor. This story restores meaning and mystery to human experience, "so that the world is once again experienced as a sacred place" (Reason, 1994, p. 10). The story is a spiritual expression and celebration of human flourishing, the goal of participatory inquiry. 


\section{Expressions of Participatory Story in Our Work}

Our research projects have been expressions of the story of participatory inquiry. Both of us share a philosophical and political commitment to the ideals of participatory inquiry. Likewise, our research journeys have led us to concerns for the well-being of women, for one (RC) of us in the context of despair and child abuse and the other (MS) in terms of culture and mental health. The story of our inquiries is the interweaving of the researcher story and the participant story into a deeper and richer our story, a story beyond individual stories.

\section{Women Survivors of Child Abuse}

My (RC) previous studies of despair in women led me to appreciate the significance of being abused as a child and how women experienced life. These women live in a participatory world and the research that I sought to create was intended to offer the possibility of creating a generative web of communion in the form of a research team. The research team was created that included 8 women survivors of child abuse, 3 research assistants, and me. The story which we have created and are continuing to create is a reflection of the constructs and sensitivities we have developed in exploring the lives of the women together. For instance, each woman has shared her storyline, her experience of how life has unfolded from being abused, and together a larger story is being told. We are interpreting what the story tells us, making propositions and developing ourselves to inquire deeper, to tell a richer story.

The story unfolds about what life is like and how healthcare has been affected by being abused. The women strive together to make sense of their actions in the past and seek more practical ways of being a part of the story. For instance, the women in the group who are mothers want desperately not to perpetuate any seeds of further abuse that might arise from their experiences and behaviors. The authors cooperate in trying to tell the story that best explains what happened and what might happen to create better lives, emphasizing that they want the story shared with other abused women.

In seeking to compose a story that is meaningful for themselves and for other women who have experienced child abuse, they use a variety of ways of knowing. They seek to know from their personal lives. They seek to know from what they have learned through the media and from professional sources. They seek to know from those they consider experts in the field. They appreciate using a wide range of knowledge to inform the story we are writing together. For instance, these women describe what they have learned from professionals and compare that to their personal experiences.

The women in the research group who have survived child abuse explore the politics of having been abused. For instance, they describe the challenges of revealing abuse including implications for the type of healthcare they receive. They consider the way resources available to them are enhanced or limited by their income, race, gender, and culture. They explore the possibilities of democratic social change that could make better the lives of all women and girls. They hope the story will educate others and will help improve the capacities of people who are affected by child abuse. 
The primary context of the story for the women who have survived child abuse in this particular research project is to promote healing. While they explore the influence of their own experiences of being abused, they look for ways in which to transcend the harm and transform themselves. For instance, we talk about how the inquiry process itself has created a deeper personal understanding of our lives and heightened the desire to develop interventions that are empowering. The story that is being told is sacred in that it is a celebration of the potential for human flourishing that comes from the research.

\section{Latino Mental Health}

My (MS) research in health disparities evolved from my previous studies that found dramatic differences between nurses' and patients' perceptions of care. I sought a research methodology that might bridge the gap between patient populations and providers, and between researchers and practitioners. Community-based participatory research (CBPR) seemed to hold the most promise as a research approach.

The Guilford County Community Coalition for Latino Mental Health is an interdisciplinary, collaborative CBPR team initiated under my leadership nearly a year ago. The coalition is composed of community members, mental healthcare providers, health advocates, public health educators, and academic researchers from two disciplines (nursing and counseling). Community partners represent the Guilford Center (Guilford County Community Mental Health Center); Mental Health Association of Greensboro; Center for New North Carolinians; Center for Youth, Family, and Community Partnerships; Head Start; and Family Solutions (private provider of mental health services). Community team members are full participants in the research process. For example, coalition members completed human subjects training, chose the study population and focus, designed the focus group interview guide and recruitment flyers, facilitated the focus groups, and will actively participate in data analysis and dissemination.

The coalition is practical and action-based. The coalition has completed one preliminary study (Shattell, Hamilton, Starr, Jenkins, \& Hinderliter, in press). This study identified individual, organizational, and community factors that affect access, use, and perceptions of mental health services for Latinos in our community, from the perspective of coalition members. Following this study, coalition members suggested that a second study should focus on women because women are more amenable to addressing mental health issues, and on depression because it is a common problem among Latinas. Also, because women are the center of families in the Latino community, coalition members thought that such a study would be a way to serve the entire family. Based on the preliminary study findings and the interest of the coalition members, the coalition planned and is currently conducting a study of Latina women to identify their mental health service needs and factors affecting their access, use, and perception of mental health services. Three focus groups in Spanish have been conducted with 30 adult Latinas, facilitated by Spanish- speaking coalition members.

The coalition members often discuss political dimensions of our research. Discussions focus on anti-immigrant sentiments in the United States and the impact that this has on individuals. Fear and isolation are overwhelming for undocumented immigrants. Immigrant populations are immensely affected by the politics of the day. We hope to engage the wider community and lawmakers and to use our findings to implement change. 
The research conducted by the coalition members is purposeful and meaningful. Coalition members freely contribute their time and effort because of a strong belief in the work. For example, some coalition members have described a personal, ethical responsibility to engage in our research partnership because of the potential positive impact on others. The partnership channels energy and provides hope.

\section{Summary}

The research as the researcher's story in our case involved an understanding of the story as a participatory composition generated from using an inquiry process that invites the co-authoring of the story for all researcher-participants. The goal of participatory inquiry, in some sense, is to tell a participatory story. This story is a story that arises from living in a participatory world, invokes practical being and acting, extends our understanding of what it is to know, promotes liberation of muted voices in the storyline, and seeks to celebrate meaning and purpose found in human flourishing in the act of composing and telling the story.

\section{References}

Heron, J. (1996). Co-operative inquiry: Research into the human condition. Thousand Oaks, CA: Sage

Macmurray, J. (1957). The self as agent. London: Faber and Faber. Reason, P. (Ed.). (1994). Participation in human inquiry. London: Sage.

Reason, P., \& Bradbury, H. (2001). Introduction: Inquiry and participation in search of a world worthy of aspiration. In P. Reason \& H. Bradbury (Eds.), Handbook of action research: Participative inquiry and practice (pp. 1-14). Thousand Oaks, CA: Sage.

Shattell, M., Hamilton, D., Starr, S., Jenkins, C., \& Hinderliter, N. (in press). Mental health service needs of a Latino population: A community-based participatory research project. Issues in Mental Health Nursing. 